\title{
PERFORMANCE OF A TURBINE RIM SEAL SUBJECT TO ROTATIONALLY-DRIVEN AND PRESSURE-DRIVEN INGESTION
}

\author{
Anna Bru Revert ${ }^{1}$, Paul F. Beard', John W. Chew ${ }^{2}$, Sebastiaan Bottenheim ${ }^{3}$ \\ ${ }^{1}$ Oxford Thermofluids Institute, Dept. of Engineering Science, University of Oxford, Oxford, OX2 0ES, UK \\ 2 Thermo-Fluid Systems UTC, University of Surrey, Guildford GU2 7XH, UK \\ ${ }^{3}$ Rolls-Royce plc, PO Box 3, Bristol, BS34 7QE, UK
}

\begin{abstract}
This experimental study considered the performance of a chute rim seal downstream of turbine inlet guide vanes (but without rotor blades). The experimental set up reproduced rotationally-driven ingestion without vanes and conditions of pressure-driven ingestion with vanes. The maximum rotor speed was 9000 rpm corresponding to a rotational Reynolds number of $3.3 \times 10^{6}$ with a flow coefficient of 0.45. Measurements of mean pressures in the annulus and the disc rim cavity as well as values of sealing effectiveness deduced from gas concentration data are presented. At high values of flow coefficient (low rotational speeds), the circumferential pressure variation generated by the vanes drove relatively high levels of ingestion into the disc rim cavity. For a given purge flow rate, increasing the disc rotational speed led to a reduction in ingestion, shown by higher values of sealing effectiveness, despite the presence of upstream vanes. At $U_{a x} /(\Omega b)=0.45$, the sealing effectiveness approached that associated with purely rotationally-driven ingestion. A map of sealing effectiveness against non-dimensional purge flow summarises the results and illustrates the combined rotational and pressure-driven effects on the ingestion mechanism. The results imply that flow coefficient is an important parameter in rim sealing and that rotational effects are important in many applications, especially turbines with low flow coefficient.
\end{abstract}

$\begin{array}{ll}\text { NOMENCLATURE } \\ b & \text { disc radius, } \mathrm{m} \\ c & \text { tracer gas concentration, } \% \\ C_{a x} & \text { axial chord, } \mathrm{m} \\ C_{d} & \text { discharge coefficient } \\ C_{w} & \text { non-dimensional purge flow rate }=\dot{m} / \mu b \\ C_{p} & \text { cavity pressure coefficient } \\ & =\left(p-p_{1011}\right) / 0.5 \rho(\Omega b)^{2} \\ C_{p, \theta \text { disc }} & \begin{array}{l}\text { circumferential pressure coefficient } \\ =\left(p_{\theta}-\overline{p_{\theta}}\right) / 0.5 \rho(\Omega b)^{2}\end{array} \\ C_{p, \theta \text { ann }} & \begin{array}{l}\text { circumferential pressure coefficient } \\ =\left(p_{\theta}-\overline{p_{\theta}}\right) / 0.5 \rho\left(U_{\text {ann }}\right)^{2}\end{array} \\ g & \begin{array}{l}\text { rim seal gap size, } \mathrm{m} \\ g\end{array}\end{array}$

$d \quad$ diameter, $\mathrm{m}$

$k \quad$ empirical constant

$\dot{m} \quad$ mass flux, $\mathrm{kg} \mathrm{s}^{-1}$

$p \quad$ pressure, bar

$\operatorname{Re}_{a x} \quad$ axial flow Reynolds number $=\rho U_{a x} C_{a x} / \mu$

$\operatorname{Re}_{\varnothing} \quad$ rotational Reynolds number $=\rho \Omega b^{2} / \mu$

$s_{c} \quad$ seal clearance $=g / b$

$T \quad$ temperature, $\mathrm{K}$

$U_{a x} \quad$ axial velocity, $\mathrm{m} \mathrm{s}^{-1}$

$U_{m} \quad$ mean flow velocity through seal in $r-z$ plane, $=\dot{m} / \rho 2 \pi b s_{c}, \mathrm{~m} \mathrm{~s}^{-1}$

\section{Greeks}

$\varepsilon \quad$ sealing effectiveness

$\lambda_{T} \quad$ turbulent flow parameter $=C_{w} / \operatorname{Re}_{\varnothing} 0.8$

$\mu \quad$ dynamic viscosity, $\mathrm{Pa} \mathrm{s}$

$\rho \quad$ fluid density, $\mathrm{kg} \mathrm{m}^{-3}$

$\Omega \quad$ angular rotational speed, $\operatorname{rad~s}^{-1}$

\section{Subscripts}

0 total conditions

ann annulus value

ax axial component value

$\max$ maximum value

min minimum value

purge purge flow value

stator stator wall value

$\theta \quad$ circumferential component

\begin{tabular}{ll}
\multicolumn{2}{c}{ Abbreviations } \\
CFD & Computational Fluid Dynamics \\
NGV & Nozzle Guide Vane \\
ORF & Oxford Rotor Facility \\
PS & Pressure Side \\
SLA & Stereolithography \\
SS & Suction Side
\end{tabular}




\section{INTRODUCTION}

For decades, the main strategy of gas turbine designers has targeted improvements in efficiency derived from an increase in the turbine entry temperature, incurring extra cooling cost and increased risk of hot gas ingestion. Overestimating the amount of secondary air required to seal the volume between the statorrotor discs existing below the hub results in an efficiency penalty whilst the undersupply of this critical sealing flow may challenge the integrity of the components to the detriment of the operating life of the engine. Therefore, a deep understanding of the underlying flow physics and accurate prediction is critical and is of paramount importance to develop adequate design tools.

Early studies of rim seal ingestion focused on the disc pumping effect that leads to rotationally-induced ingestion. This is described in reviews of turbine rim sealing by Johnson et al. [1], Scobie et al. [2] and Chew et al. [3] and illustrated, for example, by Phadke and Owen [4]. The importance of the annulus flow was acknowledged shortly after and attention subsequently shifted to the impact of turbine vanes and blades which create circumferential flow asymmetries in the main gas path and drive ingestion irrespective of the disc pumping. In many studies it has been assumed that the pressure asymmetries created by the blades and vanes dominate rim seal ingestion.

Over the last two decades, unsteady computational fluid dynamics (CFD) and fast response pressure measurements have revealed that rim seal flows are subject to rotating flow modes or inertial waves. This has provided an explanation for the limitations of steady CFD and more elementary models, and has stimulated new research aimed at clarifying the flow physics and reassessing the driving mechanisms. An experimental study by Beard et al. [5] confirmed the presence of rotating flow modes in a chute seal subject to rotationally-driven ingestion through detailed analysis of extensive fast response pressure measurements. Subsequently, Gao et al. [6] explored the physics behind these inertial waves as the third major driver for hot gas ingestion, Figure 1. This has raised new questions regarding the effects of rotation and this study aims to investigate the interaction and combined effect of the disc pumping and mainstream pressure asymmetries.

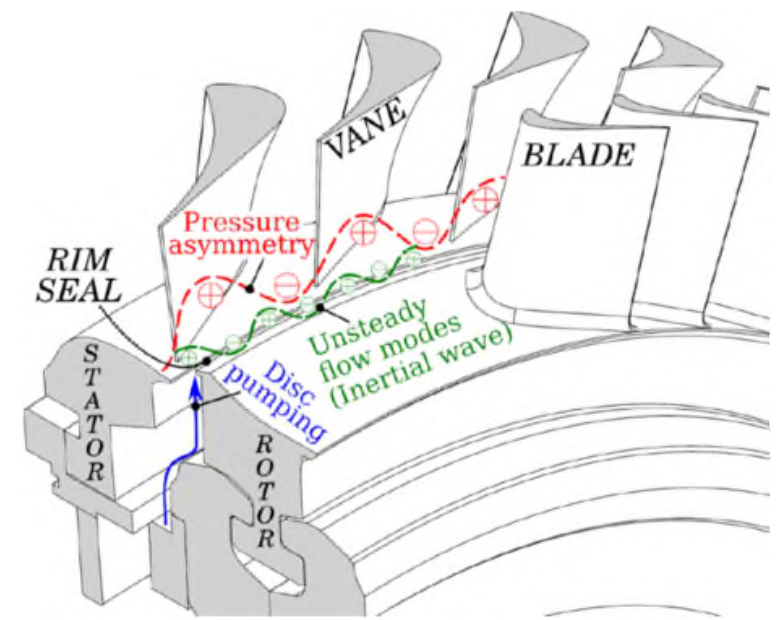

Figure 1: Driving mechanisms of rim seal ingestion [6].
The current paper reports the sealing performance of a chute turbine rim seal under three different annulus flow configurations through gas concentration measurements. Results of sealing effectiveness are presented for rotationally-driven ingestion without and with an axisymmetric annulus flow. A further degree in the complexity of the boundary conditions was introduced by vanes imposing pressure asymmetries and generating a swirl component. Rotor blades were not included in this study and the cavity set up remained identical between the configurations, therefore any variations in sealing performance can be attributed to the changes in main gas path flow conditions. By decoupling each individual contribution, the fundamentals of hot gas ingestion are addressed. The influence of four variables: purge flow (and mass flux ratio), pressure asymmetries in the annulus flow, disc speed and rim seal clearance was investigated.

A brief summary of the relevant published work to date is first presented, followed by an outline of the experimental facility and test section, including instrumentation and operating test conditions. Subsequently, the pressure fields in the cavity and the main gas path are analysed. The sealing performance of the chute seal is then discussed, concluding with a map of sealing effectiveness that summarises the effect of the three main ingress-defining non-dimensional parameters investigated.

\section{LITERATURE REVIEW}

The earliest published data on turbine rim sealing was obtained by Bayley and Owen [7]. They considered rotationallyinduced ingestion for a simple axial clearance seal and produced a correlation for the minimum flow required to prevent ingestion. In the open literature, Abe et al. [8] were the first to recognise the relevance of the pressure asymmetries in the annulus gas path in driving hot gas ingestion. Further to this, Phadke and Owen [4] and [9] defined two regimes based on the dominating mechanism in hot gas ingestion: rotationally-induced ingestion would occur at low $\mathrm{Re}_{a x} / \mathrm{Re}_{\varnothing}$ when the disc pumping effects prevail, whilst externally-induced ingestion would take place when the ratio $\mathrm{Re}_{a x} / \mathrm{Re}_{\emptyset}$ is large and the external pressure asymmetries govern ingress. The latter scenario would imply predominance of $\mathrm{Re}_{a x}$ and independence (or negligible effect) of $\mathrm{Re}_{\emptyset}$, expected to be a few orders of magnitude lower.

In an engine-realistic turbine stage, the nozzle guide vanes $(\mathrm{NGVs})$ in the gas path create recurring regions of high pressure and low pressure downstream of the NGV trailing edge. This is illustrated in Figure 1. If the disc cavity pressure is below the annulus pressure, ingress of flow from the mainstream into the cavity is expected. Protrusions at the rim of the stator disc form a rim seal that, in combination with an imposed purge flow, aim to pressurise the cavity and prevent ingestion of mainstream flow. The presence of the rotor blades downstream of the NGVs introduces further complexity to the already convoluted flow field at the rim seal region that experiences the synergetic interaction of the purge flow, mainstream flow, hot gas ingestion and NGV potential field asymmetries.

Various elementary models have been proposed for the correlation of measured rim sealing performance data and 
incorporation in industrial design methods. Chew [10] developed a method for estimating the disc pumping effect and rotationallyinduced ingestion in closed rotor-stator systems in the absence of external flow. For the small seal clearances considered, the minimum flow rate required to seal the cavity and the sealing effectiveness for flow rates below this value are given by Eq. 1 . The parameter $k$ is adjusted to fit the data for different rim seal geometries and gives an indication of the sealing performance; low $k$ implies better prevention or suppression of ingestion.

$$
\frac{U_{m, \min }}{\Omega b}=0.1214 k
$$

$$
\varepsilon=\frac{1}{0.8+0.02428 k\left(\Omega b / U_{m}\right)} \text { for } 0<U_{m}<U_{m, \min }
$$

Where $U_{m}$ is the mean seal velocity based on the supplied purge flow rate, $\Omega$ is the rotor angular speed, $b$ is the rim seal radius, and $\varepsilon$ is the sealing effectiveness which is defined later in relation to experimental measurements. For $k=0.8$, the model gives $C_{w, \min }=0.61 s_{c} \operatorname{Re}_{\varnothing}$, where $s_{c}$ is the seal clearance, reproducing Bayley and Owen's correlation for a simple axial clearance seal.

Hamabe and Ishida [11] were amongst the first of many researchers to compare sealing effectiveness based on gas concentration measurements with an elementary 'orifice model' of pressure-driven ingestion. Approximating the circumferential annulus pressure variation (between $p_{\theta, \min }$ and $p_{\theta, \max }$ ) as sinusoidal and adopting a uniform cavity pressure, they derived Eq. 2 for the minimum sealing flow rate. This is obtained by integrating around the annulus assuming locally onedimensional flow through an orifice area corresponding to the seal clearance. With appropriate choice of discharge coefficient, $C_{d}$, the orifice model may be adjusted to match measured minimum sealing flows and sealing effectiveness.

$$
\frac{U_{m, \min }}{\Omega b}=C_{d} \frac{2}{\pi} \sqrt{\frac{p_{\theta, \max }-p_{\theta, \min }}{0.5 \rho(\Omega b)^{2}}}
$$

Several research groups have conducted numerical and experimental investigations to assess the various factors affecting rim seal flows. For example, Green and Turner [12] and Bohn et al. [13] studied the effects of removing the rotor blades from the gas path and found that the axial rim seal performed more effectively with the rotor blades. The presence of largescale unsteady flow features in the cavity was first reported by Cao et al. [14] in a combined experimental and numerical study. The CFD results indicated that, for the turbine studied, ingestion was rotationally-driven rather than pressure-driven.

Interest in this area of research has increased in recent years as gas turbine designers seek to improve the overall cycle efficiency by reducing the penalty derived from the secondary air system. Examples of recent research are given by Savov et al. [15], Hualca et al. [16] and Horwood et al. [17]. Despite a wide variety of rim seal geometries having been investigated, there are relatively few studies with chute seals as considered in this paper. Hence the results for chute seals presented by
Horwood et al. [17], Gentilhomme et al. [18] and Boudet et al. [19] are of direct relevance to the current study. An earlier investigation by Phadke and Owen [4] included rotationallydriven ingestion measurements for a 'mitered' seal which may be regarded as a 'high angle chute' seal. It was concluded that the mitered seal would only be outperformed by the radial seal.

The investigation reported in this paper provides experimental data for a chute seal operating under the influence of the rotor disc pumping and external pressure asymmetries. Experimental data have been acquired with the aim of clarifying the relative importance of rotationally and pressure driven ingestion on the sealing performance of the chute seal.

\section{EXPERIMENTAL SETUP}

All experiments were conducted in the Oxford Rotor Facility (ORF), a transient facility originally designed to study the aero-thermal behaviour of transonic high pressure turbines at engine representative conditions [20]. Recently, the facility has been adapted to investigate the aerodynamics in turbine secondary air systems rather than the main gas path. The details of the facility working section, air supply system and instrumentation installed in this study are described below.

\section{Working section design}

The geometrical features of the ORF working section as well as the purge feed path are detailed in Figure 2(a). Purge flow enters an annular cavity upstream of the feed distributor (4) and is then introduced into the rotor disc cavity between the labyrinth seal (5) and upper overlapping seal. A circumferentially uniform purge is promoted by feeding the sealing flow through 60 evenly distributed holes of $2.5 \mathrm{~mm}$ diameter. A blockage ring at the exit of the feed holes breaks down any jetting and promotes mixing of the flow prior to entering the rotor cavity through an annular slot. A secondary air feed beneath the labyrinth seal is available to mitigate leakages. Beard et al. [5] determined that the pressure across the labyrinth seal was balanced and the volume sealed. Hence, this auxiliary feed was not required in this study.

For all experiments, the rotor hub platform (1) and the hub vane ring (2) were solid and axisymmetric rings that included the rim seal design. The ORF includes a split disc (3) allowing modification to the rotor seal geometry by simply replacing the rotor hub platform component. However, the results presented here correspond to a fixed seal geometry.

Radial growth of the rotor disc has been accounted for in the chute seal design providing the desired nominal seal clearance of $1 \mathrm{~mm}$ at the maximum rotational speed of $9000 \mathrm{rpm}$. The nominal axial overlap at the rim seal was $2 \mathrm{~mm}$ with a distance of $10 \mathrm{~mm}$ between the stator wall and rotor disc in the cavity region immediately below the rim seal. An offdesign condition simulating rearward displacement of the rotor disc was also studied. A $2.5 \mathrm{~mm}$ spacer ring was positioned between the disc and the shaft providing a rim seal gap size of $1.85 \mathrm{~mm}$. With this axial displacement there was no axial overlap of the seal, rather a $0.5 \mathrm{~mm}$ axial gap between the stator and rotor seal rims. The rim seal and cavity geometry are identical to those previously studied by Beard et al. [5]. 


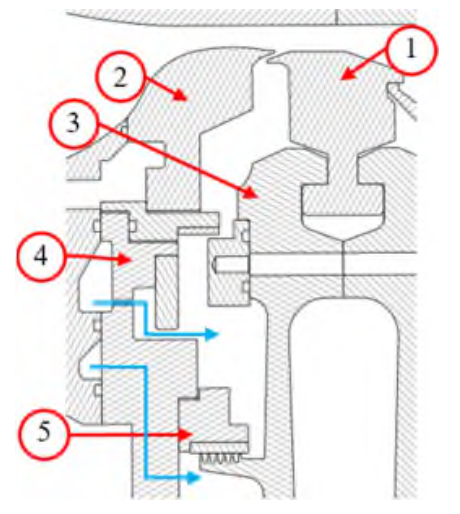

(a)

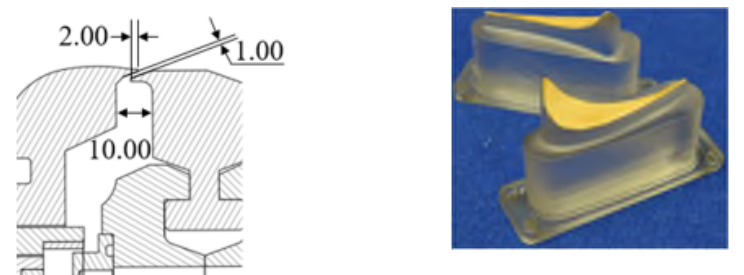

(a)

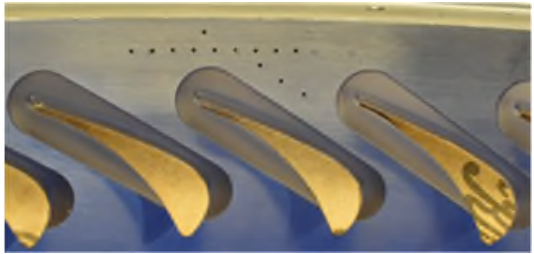

(b)

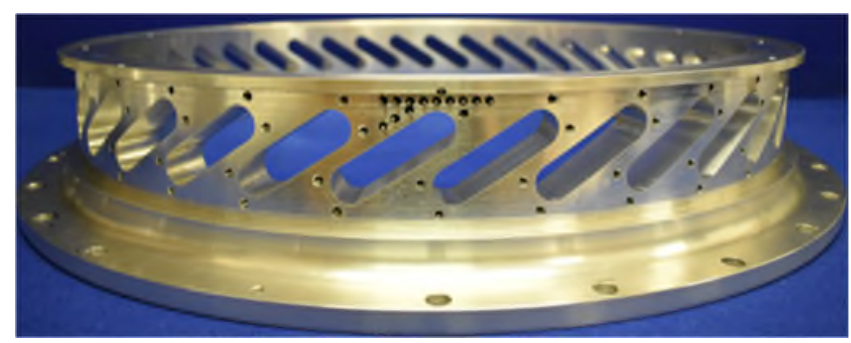

(c)

Figure 3: Photographs of: (a) SLA NGVs, (b) Assembly of NGVs in casing mounting ring, (c) Casing mounting ring.

The mainstream feed passed through two metering nozzles in parallel and was introduced into a large settling tank before entering the working section. The mainstream mass flow was kept constant for all tests (whenever present). The purge flow passed through a single metering nozzle and went into a manifold that distributed the flow through 8 flexible hoses. The hoses were installed evenly around the circumference of the facility to an annular settling volume in the working section. Variation of the purge flow rate was achieved by adjusting the area of the sealing air nozzle between tests.

Total pressure and temperature measurements were acquired upstream of each nozzle. The uncertainty associated with the measurement of the mainstream mass flux was $\pm 0.7 \%$, whereas for the purge mass flux uncertainty ranged between \pm 0.75 and $\pm 2.0 \%$ depending on the nozzle diameter.

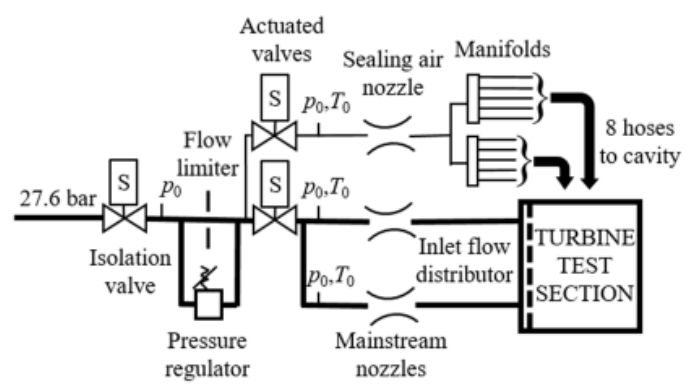

Figure 4: Schematic of mainstream and purge air feed system.

To reduce measurement uncertainty, for test conditions with low purge mass flux conditions $\left(\dot{m}_{\text {purge }}<0.035 \mathrm{~kg} \mathrm{~s}^{-1}\right.$ ), the purge flow was instead metered by an Alicat MC Series 2000 mass flow controller, with a traceable uncertainty of $\pm 0.8 \%$ of reading plus $\pm 0.2 \%$ of full scale. Together with the previously described reduced annulus area, a steady test time of up to 20 minutes was possible at the test conditions detailed in Table 1. 


\section{INSTRUMENTATION}

Comprehensive measurements of steady pressure and temperature were taken throughout the working section to ensure the desired test conditions were achieved in the main gas path and stator-rotor cavity. Flexible vinyl tubes of $1.6 \mathrm{~mm}$ diameter connected pressure tappings and pitot rakes in the working section with pneumatic pressure transducers. Absolute values were measured in the main gas path with First Sensor Series CTE8000 pressure transducers with a nominal uncertainty of $\pm 0.1 \%$ of the full-scale output, whilst pressure measurements inside the cavity were acquired with differential First Sensor Series BTEM5000 pressure transducers with a nominal uncertainty of $\pm 0.2 \%$ of the full-scale output. K-type bare bead thermocouples $(d=76.2 \mu \mathrm{m})$ were installed with exposed tips to provide gas temperature measurements with an uncertainty of $\pm 0.45 \%$ (or $\pm 1.3 \mathrm{~K}$ ). Data was acquired by a National Instruments PXI/SCXI data acquisition system at a frequency of $200 \mathrm{~Hz}$.

\section{Mainstream gas path}

The mainstream velocity above the rim seal was obtained from measurements of static pressure, total pressure and total temperature. Radial rakes of four pitot tubes located upstream of the annulus area contraction - see Figure 5(a) - provided data of mainstream total pressure at four circumferential locations spaced $90^{\circ}$ apart. Similarly, four radial rakes each with four k-type thermocouples were equally spaced at the same axial coordinate to measure the mainstream total temperature.

Without vanes present, the annulus static pressure was sampled at nine axially distributed positions on the reduced annulus casing wall above the seal and repeated at $90^{\circ}$ intervals, as shown in Figure 5(a).

With the vanes present (non-axisymmetric flow case), the configuration of annulus static pressure measurements was modified and is indicated by the layout shown within the dashed grey box in Figure 5(a). The axial measurement points corresponded to the six most downstream locations without NGVs present, and started roughly at the axial position of the vane trailing edge. In this configuration, the tappings were approximately aligned in the streamwise direction at midpassage and again replicated at 4 evenly spaced circumferential locations. The arrangement of the measurement points can also be observed in relation to the NGVs in Figure 3(b). For this configuration, the circumferential variation of static pressure downstream of the NGVs was also measured at the reduced casing annulus wall at nine locations evenly spaced over one vane pitch and $33 \%$ of a vane axial chord downstream of the vane trailing edge. These measurement locations can also be seen in the layout sketch in Figure 5(a) and in Figure 3(b).

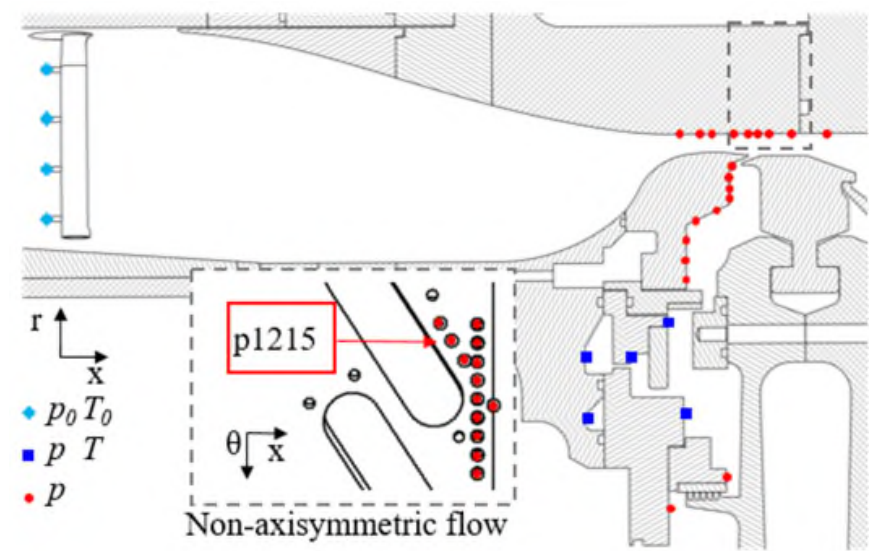

(a)

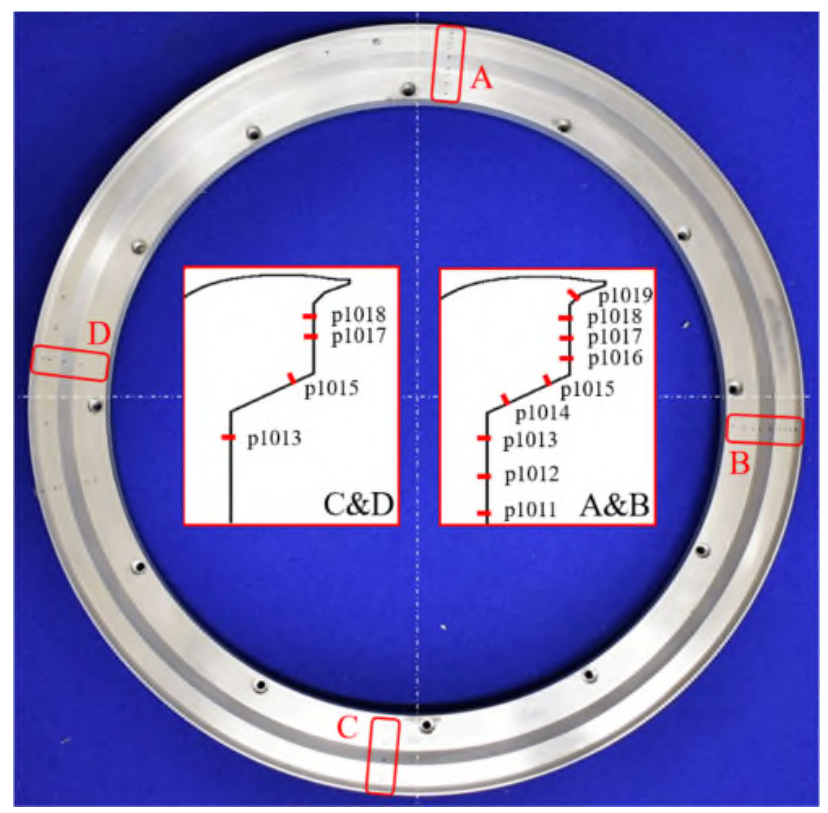

(b)

Figure 5: ORF measurement locations: (a) Main gas path, purge flow feed system and rotor cavity, (b) Rim seal cavity.

\section{Cavity and purge feed system}

The purge flow introduced into the rotor cavity was monitored throughout the feed distributor with the pressure and temperature measurements shown by dark blue squares in Figure 5(a). The pressure difference across the labyrinth seal separating the rotor cavity and inner cavity was also measured to ensure the inner cavity remained sealed across the test campaign. The radial distribution of static pressure on the stator wall in the rim seal cavity was measured at four equispaced circumferential locations labeled A-D in Figure 5(b). Locations A and B included nine radially spaced pressure tappings, whilst locations $\mathrm{C}$ and $\mathrm{D}$ included four repeat measurement points. Measurements were referenced to the furthest inbound tapping for each set of radial measurements (p1011 and p1013 respectively). 


\section{Sealing effectiveness measurement system}

Sealing effectiveness data can be used as a measure of ingestion of mainstream annulus flow into the cavities existing beneath the annulus hub. The tracer gas technique consists of seeding the purge flow that is introduced into the cavity with a foreign gas, commonly carbon dioxide, whilst the mainstream flow is kept at atmospheric composition. Measurement of tracer gas concentration in the air mixture then indicates ingestion when the concentration falls below that supplied to the cavity, meaning that the extra air from the mainstream has diluted the air- $\mathrm{CO}_{2}$ mixture. The performance of the seal against ingestion can be quantitatively represented by the sealing effectiveness:

$$
\varepsilon=\frac{c_{\text {stator }}-c_{\text {ann }}}{c_{\text {purge }}-c_{\text {ann }}}
$$

which can take values between 0 (100\% ingestion - only mainstream flow) and 1 (no ingestion - solely purge flow).

$\mathrm{CO}_{2}$ concentration measurements were acquired using a dual channel Pulsar IV Non-Dispersive Infra-Red multi-gas analyser from Signal Group. This device offers a sensor response time of under 2 seconds with linearity and repeatability below $\pm 0.5 \%$ and $\pm 0.1 \%$ of full scale respectively. A schematic of the sealing effectiveness measurement system is shown in Figure 6. A multiplexer allowed sequential sampling of up to 20 measurement points through channel 1 , whilst channel 2 was used to continuously monitor the concentration of the purge air at the entry of the rim seal cavity. The multiplexer remained at each measurement point for $30 \mathrm{~s}$, achieving a stable reading (deviation of $\pm 0.02 \%$ concentration from mean value) after approximately $17 \mathrm{~s}$. Seal effectiveness data was only calculated once a stable reading was reached. Repeatability of seal effectiveness measurements between tests was typically $\pm 0.07 \%$. A constant input of nitrogen purged the measurement cells expelling the sample gas, as well as defining the zero concentration calibration point. Compressed gas bottles of certified $\mathrm{CO}_{2}$-air mixtures of $2 \%$ and $4 \% \mathrm{CO}_{2}$ concentration $( \pm 1 \%$ uncertainty in concentration percentage) provide two other span points to complete a three-point calibration curve. The analyser channels were calibrated daily before the start of testing.

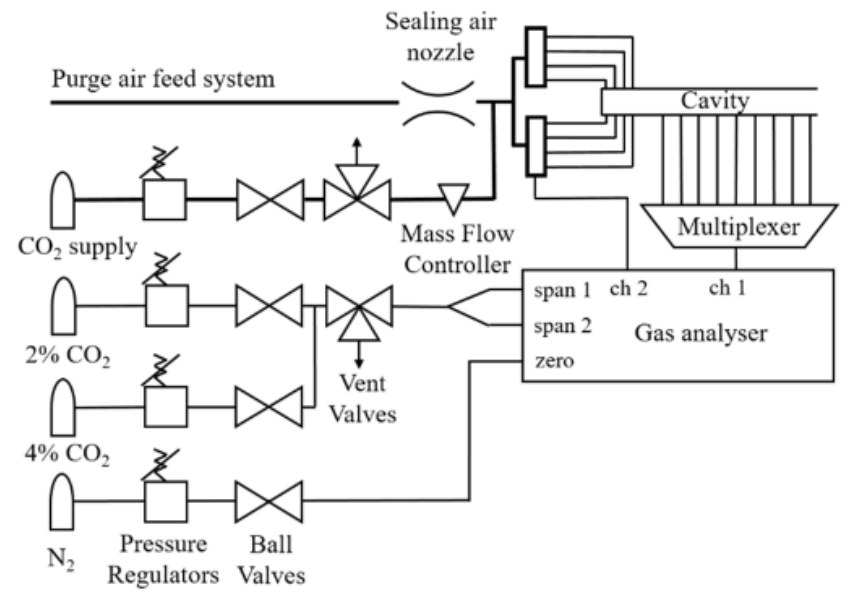

Figure 6: ORF sealing effectiveness measurement system.
$\mathrm{CO}_{2}$ was introduced into the purge flow downstream of the purge flow choked metering nozzle and prior to the distribution manifold. Preliminary tests during commissioning of the new system demonstrated that the air and carbon dioxide in the purge flow were fully blended, the gas mixture entering the cavity was homogeneous. The $\mathrm{CO}_{2}$ mass flux was set by an Alicat MCR mass flow controller and recorded as a $0-5 \mathrm{~V}$ proportional output signal. The quoted accuracy for the mass flow controller is $\pm 0.8 \%$ of reading plus $\pm 0.2 \%$ of full scale. A $3 \% \mathrm{CO}_{2}$ concentration in air was used in this study.

Measurements of $\mathrm{CO}_{2}$ concentration were taken at nine radial positions along the stator wall of the rim seal cavity $\left(c_{\text {stator }}\right)$ - using the static pressure tappings at location B in Figure 5(b). The concentration of the mainstream annulus flow $\left(c_{\text {ann }}\right)$ was sampled from the static pressure tapping p1215 in Figure $5(\mathrm{a})$ and the seeded purge flow $\left(c_{\text {purge }}\right)$ was monitored for reference at the entry of the test section. The associated absolute uncertainty with the sealing effectiveness measurement was \pm 0.068 . In absence of mainstream annulus flow, the main gas path was vented with a very weak axial flow to flush the tracer gas and prevent $\mathrm{CO}_{2}$ build-up in the annulus that could potentially lead to re-ingestion of the seeded flow.

\section{TEST MATRIX}

The different operating conditions investigated in this parametric study are summarised in Table 1, whereas Table 2 shows the rotational Reynolds numbers and flow coefficients for the tests at each rotor speed considered. The variation of purge flow is captured by the non-dimensional purge flow ratio, $U_{m} / \Omega b$. Values of non-dimensional (purge) mass flow, $C_{w}$, as commonly used in air systems are also given. When present, the mainstream axial velocity component was kept constant throughout all the experiments. Rotational speed, seal clearance $\left(s_{c}=4.2 \times 10^{-3}\right.$ and $\left.7.8 \times 10^{-3}\right)$, purge flow rate and annulus flow conditions were the handle variables in this experimental study.

Table 1: Experimental test matrix ( ${ }^{\#}$ denotes test condition for non-axisymmetric annulus flow only).

\begin{tabular}{cccc}
\hline \hline & $U_{m} /(\Omega b)(-)$ & $C_{w}$ & $\operatorname{Re}_{\varnothing}(-)$ \\
\hline No external flow & $0.01-0.11$ & $820-4200$ & $3.8 \times 10^{5 \#}$ \\
& & & $1.5 \times 10^{6}$ \\
Axisymmetric flow & $0.01-0.65$ & $850-40000$ & $2.3 \times 10^{6}$ \\
Non-axisymmetric & $0.03-1.3$ & $3500-30000$ & $3.3 \times 10^{6}$ \\
flow & & & \\
\hline \hline
\end{tabular}

Table 2: Rotational Reynolds number and flow coefficient at tested rotor speeds for tests with swirled annulus flow.

\begin{tabular}{ccc}
\hline \hline$\Omega(\mathrm{rpm})$ & $\operatorname{Re}_{\varnothing}(-)$ & $U_{a x} /(\Omega b)(-)$ \\
\hline 1000 & $3.8 \times 10^{5}$ & 4.05 \\
4000 & $1.5 \times 10^{6}$ & 1.01 \\
6000 & $2.3 \times 10^{6}$ & 0.67 \\
7850 & $2.9 \times 10^{6}$ & 0.52 \\
9000 & $3.3 \times 10^{6}$ & 0.45 \\
\hline \hline
\end{tabular}




\section{MEAN FLOW RESULTS}

Steady pressure measurements in the cavity and the annulus are presented in this section. The mean circumferential pressure coefficient in the annulus defined with annulus flow velocity and rotor disc speed has been studied to assess the relative contribution of the external pressure asymmetries and the disc pumping effect.

\section{Mean cavity pressure}

Examples of radial profiles of the mean pressure coefficient on the stator disc are shown in Figure 7. These correspond to the smaller seal clearance and a constant purge flow rate of $C_{w}=3500\left(U_{m} / U_{a x}=0.08\right)$. Results with and without vanes are given at two values of non-dimensional purge flow ratio corresponding to $\operatorname{Re}_{\varnothing}=1.5 \times 10^{6}$ (left) and $\operatorname{Re}_{\varnothing}=2.9 \times 10^{6}$ (right) respectively. The cavity pressure coefficient, $C_{p}$, has been referenced to the measurement point located furthest inboard in the cavity, and the dynamic head at disc rim speed has been used for non-dimensionalisation.

For the rotational Reynolds numbers shown, the flow in the cavity is expected to be fully turbulent with boundary layers on each wall separated by a rotating core. Typically, for turbulent flow in shrouded rotor-stator cavities, the core vortex rotates at approximately $43 \%$ of the rotor disc speed. The vortex strength may be affected by mainstream ingestion, cavity geometry, purge flow rate and rotor speed. The combined effects of purge flow rate and rotor speed can often be captured by the turbulent flow parameter (or throughflow parameter), $\lambda_{T}=C_{w} / \operatorname{Re}_{\emptyset}{ }^{0.8}$, where $C_{w}=\dot{m} / \mu b$ is the non-dimensional flow rate. The data shown in Figure 7 correspond to throughflow parameter values of approximately 0.04 (left) and 0.02 (right) respectively. The two different slopes in all radial profiles of $C_{p}$ in Figure 7 suggest a change in the swirl velocity between the outer and inner parts of the cavity at the inflexion point in the geometry of the stator wall. Lines indicating pressure distributions for various forced vortices strengths matching the slopes in the radial distributions are also plotted for reference.

For the test cases without vanes (no annulus flow and axisymmetric annulus flow), Figure 7 shows that the outer and inner cavity swirl velocities increase as the rotational Reynolds number is increased. For example, without annulus flow the swirl velocity in the outer cavity goes up from approximately $44 \%$ to $47 \%$. This is consistent with a change in throughflow parameter, as described above.

Interestingly, results for the vaned configuration at the two speeds are in close agreement implying a suppression of the sensitivity to rotational Reynolds number. This is attributed to ingestion of highly swirled annulus flow in this configuration compensating for the increase in vortex strength expected from the reduction in $C_{w} / \operatorname{Re}_{\varnothing}{ }^{0.8}$. The effect of rotation on ingestion is further explored in the following section.

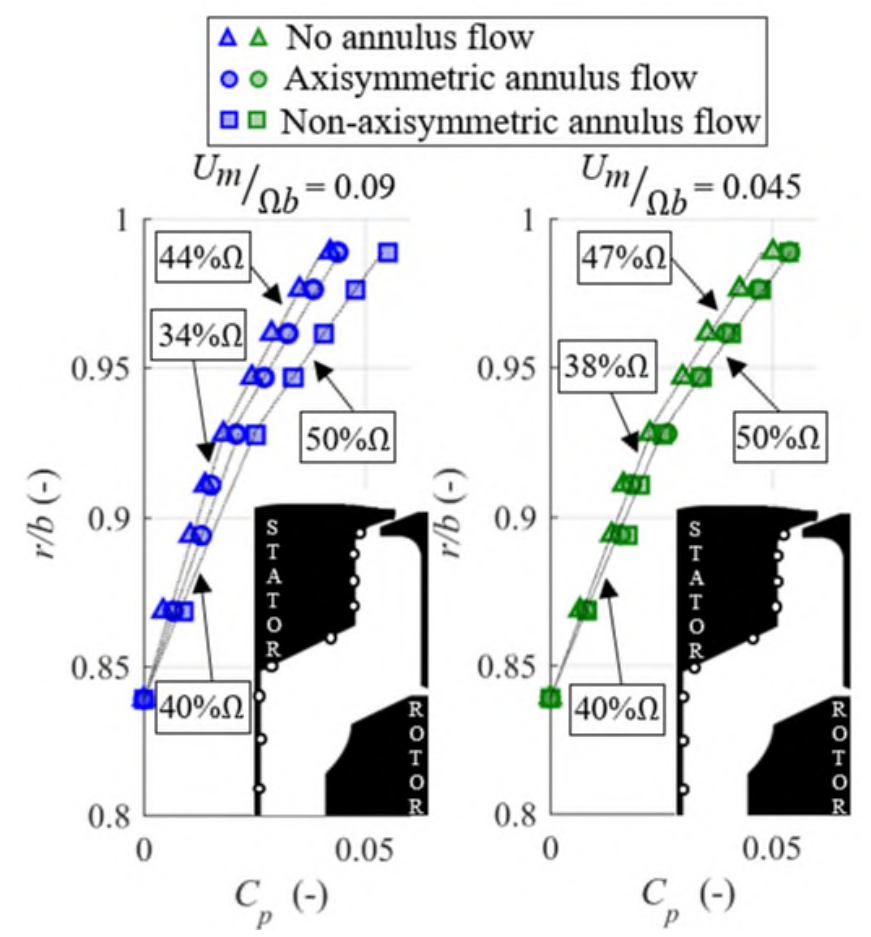

Figure 7: Mean pressure coefficient radial profile inside the cavity without annulus flow, with axisymmetric and nonaxisymmetric annulus flow for $s_{c}=4.2 \times 10^{-3}, U_{m} / U_{a x}=0.08$ left: $U_{m} /(\Omega b)=0.09\left(\operatorname{Re}_{\varnothing}=1.5 \times 10^{6}\right)$, right: $U_{m} /(\Omega b)=0.045\left(\operatorname{Re}_{\emptyset}=2.9 \times 10^{6}\right)$.

\section{Annulus pressure asymmetry}

The circumferential pressure variation downstream of the NGVs was measured on the reduced annulus casing wall, at $r / b=1.03$. These pressure measurements were obtained at nine equispaced points on the casing wall covering a single NGV pitch of 10 degrees. The data are plotted in Figure 8 as circumferential mean pressure coefficient, $C_{p, \theta}$, for a purge flow rate corresponding to $U_{m} / U_{a x}=0.08, s_{c}=4.2 \times 10^{-3}$, and four values of flow coefficient varying from $U_{a x} /(\Omega b)=1.01(4000$ $\mathrm{rpm})$ to $U_{a x} /(\Omega b)=0.45(9000 \mathrm{rpm})$. Note that the annulus flow was constant and the rotor disc speed was the only variable parameter. Two approaches for non-dimensionalisation of $C_{p, \theta}$ have been used. In the upper plot, the dynamic head is calculated using the annulus flow velocity providing values of $C_{p, \theta \text { ann }}$, whilst in the lower plot the dynamic head is based on the rotor disc rim speed giving results of $C_{p, \theta \text { disc }}$.

The distribution of $C_{p, \theta a n n}$ shows little variation with rotor disc speed implying the vane wakes are unaffected by the purge flow. Looking at the $C_{p, \theta d i s c}$ circumferential profile instead, Figure 8 suggests that the annulus pressure asymmetry should be significant (compared to rotational effects) at all conditions studied. At the highest tested rotor speed of $9000 \mathrm{rpm}$, the minimum-to-maximum pressure variation is approximately $20 \%$ of the disc speed dynamic head. 


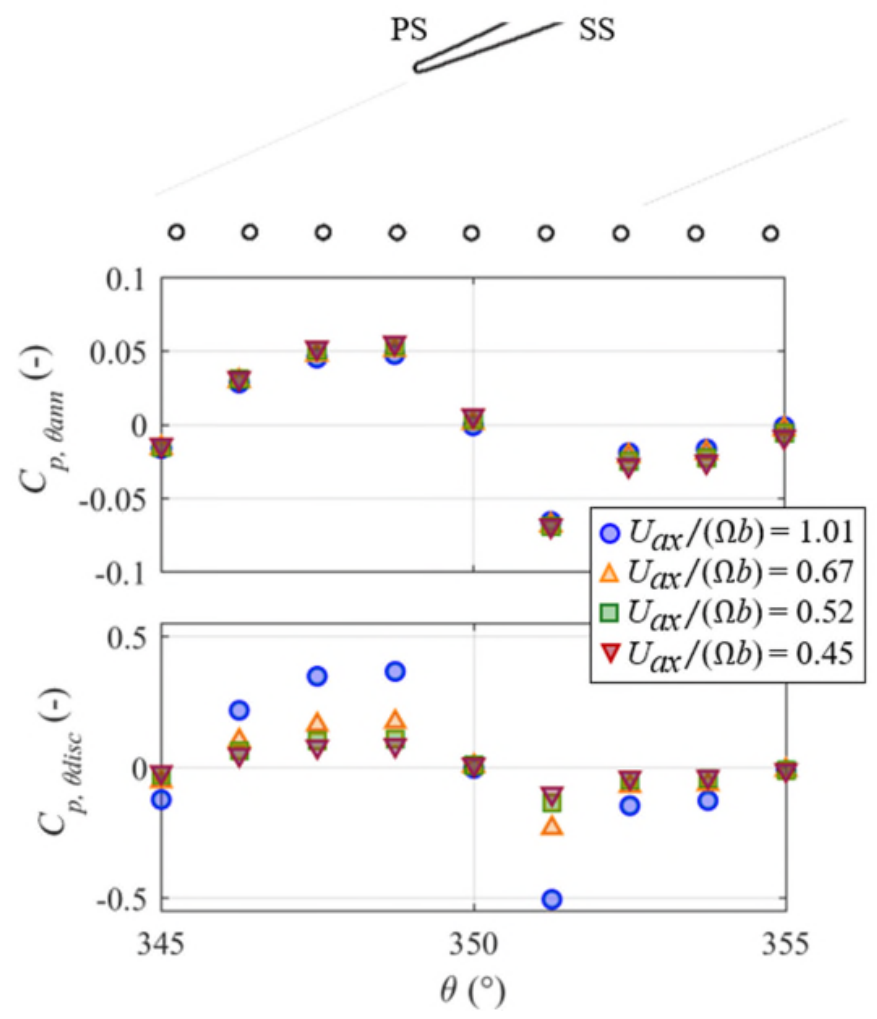

Figure 8: Effect of $\operatorname{Re}_{\varnothing}$ on $C_{p, \theta}$ over one NGV pitch for $s_{c}=4.2 \times 10^{-3}$ and $U_{m} / U_{a x}=0.08$ referenced to: (upper plot) the annulus flow, $C_{p, \theta a n n}$; and (lower plot) the rotor disc speed, $C_{p, \theta \text { disc }}$.

\section{SEALING PERFORMANCE RESULTS}

Results of sealing effectiveness under different conditions of purge flow rate, rim seal gap size, rotational speed and annulus flow conditions are assessed in this section. Comparisons against the disc pumping correlation by Chew [10] and the simple orifice model for pressure-driven ingestion by Hamabe and Ishida [11] are also included.

\section{Disc pumping results}

Several geometries under pure disc pumping effect have been explored by other research groups, although exclusively rotationally-induced ingestion for a chute seal has only previously been reported by Bru Revert et al. [21]. Results of sealing effectiveness against $U_{m} /(\Omega b)$ for the tested chute seal are plotted as blue triangles in Figure 9. Experimental data from Sangan et al. [22] for an axial seal (red squares) and radial seal (green circles) have also been included, as well as correlation curves (lines) derived by Chew [10] - see Eq. 1 - to predict sealing effectiveness of a rim seal under the disc pumping effect alone. Silhouettes for the chute seal tested in this study and the designs tested by Sangan et al. are also shown in Figure 9, as well as those used to originally fit the orifice model by Chew.

The rotationally-induced ingestion results from Sangan et al. show a similar variation of effectiveness with purge flow rate to the disc pumping model. For the radial seal, the data falls close to the Chew model with $k=0.4$ as associated with earlier results for a simple radial clearance. For an axial seal, the Sangan et al. data show significantly better sealing performance than the Chew model for $k=0.8$ (associated with previous data for a simple axial clearance seal) displaying better alignment with the predicted value for a different type of axial seal associated with $k=0.65$. This could be due to the difference in seal geometries, or possible re-ingestion of purge air from the annulus in these experiments associated with incomplete venting of the annulus.

As the chute seal includes both radial and axial variation its performance may be expected to lie between that of the axial and radial seals, as demonstrated by Phadke and Owen [4] for their 'mitered' seal. However, results indicate that the chute seal performs worse than the radial and axial seal geometries. The chute, radial and axial seals are fully sealed with $U_{m} /(\Omega b)$ values of approximately $0.12,0.05$ and 0.075 respectively. The performance of the chute correlates well to the disc pumping model with $k=1$. However, it should be noted that the axial gap for the tested chute seal is a factor of 2.9 higher than an axial seal with the same clearance. Hence, the chute seal outperforms the axial seal for the same axial seal gap, and the clearance is much less sensitive to axial movement of the rotor.

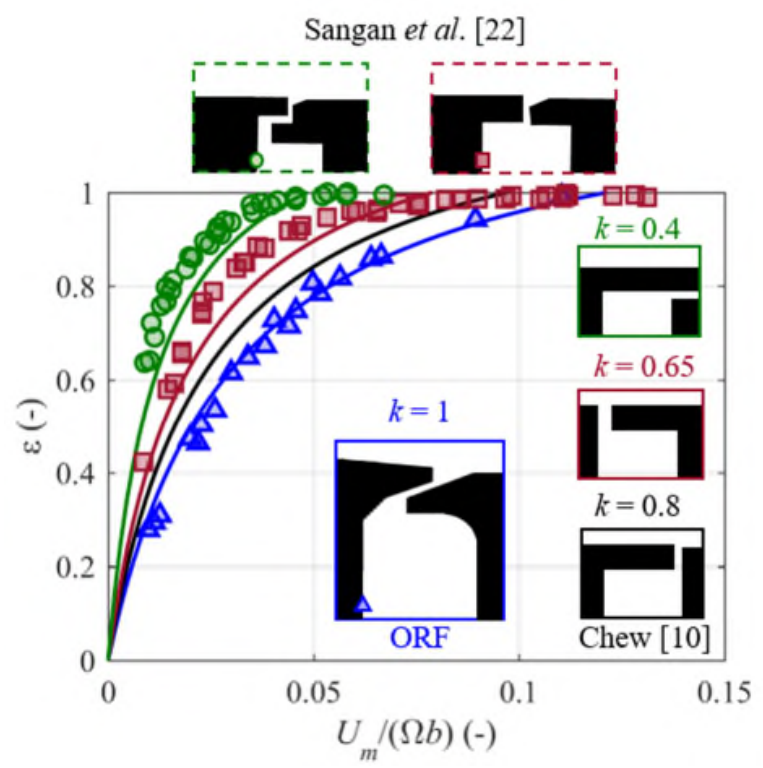

Figure 9: Comparison of ORF chute seal sealing effectiveness against non-dimensional flow rate at $r / b=0.96$ curves with

comparison to previous data [22] and correlation [10].

\section{Effect of mainstream flow conditions}

Radial distributions of sealing effectiveness on the stator wall under three different conditions of annulus flow are represented in Figure 10 for constant $\operatorname{Re}_{\emptyset}=1.5 \times 10^{6}$ (4000 rpm) and $C_{w}=3500$ (corresponding to $U_{m} / U_{a x}=0.08$ ). At these test conditions, the addition of axisymmetric flow in the annulus induced a $5 \%$ reduction in the sealing capability of the chute seal under rotationally-induced ingestion. 


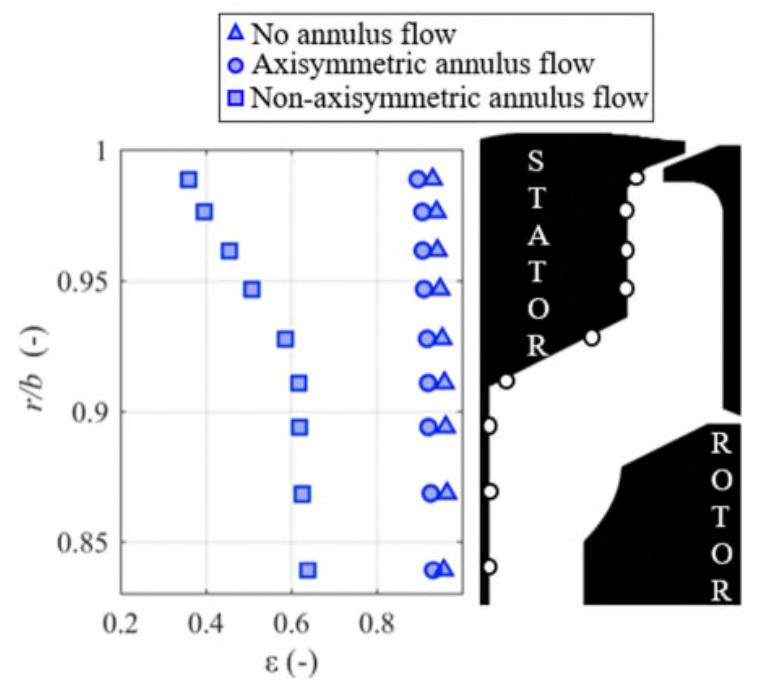

Figure 10: Effect of the external flow conditions in the sealing effectiveness radial distribution at $C_{w}=3500$

$\left(U_{m} / U_{a x}=0.08\right)$ at $\operatorname{Re}_{\emptyset}=1.5 \times 10^{6}$ and $s_{c}=4.2 \times 10^{-3}$.

With non-axisymmetric annulus flow, the introduction of swirl and circumferential variations in pressure and velocity in the annulus by the presence of vanes, drastically reduced the sealing effectiveness by $33 \%$ in the inner cavity and $60 \%$ near the rim seal. Under these circumstances, the ingestion mechanism is driven by the annulus pressure asymmetries. For the cases without annulus flow and axisymmetric annulus flow, the cavity appears to be almost fully sealed with a uniform radial profile of sealing effectiveness. However, for the vaned configuration, the outer part of the cavity appears to be significantly affected by the entrainment of mainstream flow causing a remarkable decrease in sealing effectiveness in the proximity of the rim seal.

The effectiveness profiles in Figure 10 for cases with annulus flow (without and with vanes) are reproduced in Figure 11(a), alongside results at higher rotor speeds (lower flow coefficients). The purge and annulus flow rates and seal clearance are identical for all data in this figure. Hence, these results show the effect of rotational speed for the cases without (Figure 11 left) and with vanes (Figure 11 right). As shown in Table 2, the speed variation corresponds to variation in flow coefficient which reflects the balance of rotational and pressuredriven ingestion when vanes are present.

Figure 10 shows an evident deterioration of the sealing performance at all radial positions when pressure asymmetries in the annulus are induced by the NGVs. However, Figure 11(a) reveals a very interesting inversion of the effect of rotational speed in combination with the external flow conditions. To the authors' knowledge, this has not been previously identified. For the case with axisymmetric annulus flow, the increase in rotor speed induces a stronger pressure difference across the rim seal, and more annulus flow is entrained into the cavity - Figure 7.

In the case of non-axisymmetric annulus flow, a decrease in the flow coefficient (originated by an increase in the rotational speed), results in higher sealing effectiveness, indicative of less annulus flow being entrained into the cavity.

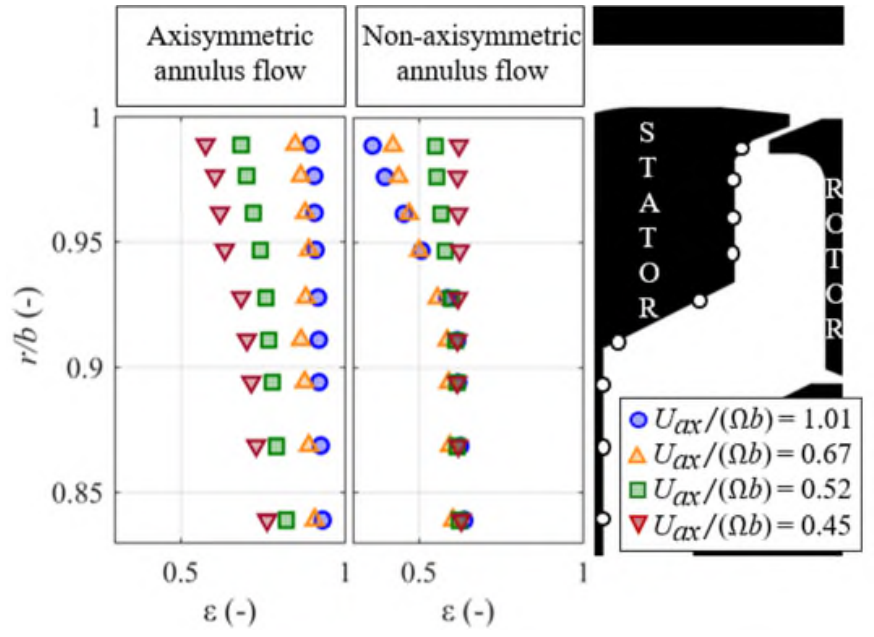

(a)

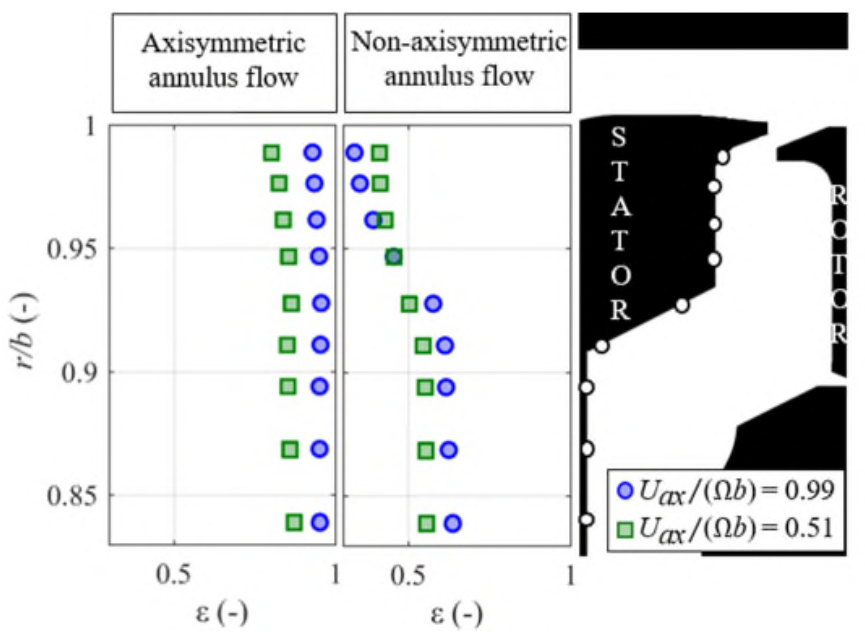

(b)

Figure 11: Effect of rotation and annulus pressure asymmetries at: (a) $C_{w}=3500\left(U_{m} / U_{a x}=0.08\right)$ for $s_{c}=4.2 \times 10^{-3}$,

(b) $C_{w}=4800\left(U_{m} / U_{a x}=0.06\right)$ for $s_{c}=7.8 \times 10^{-3}$.

Therefore, Figure 11(a) suggests that fostering the disc pumping effect with higher rotor speeds aids the sealing performance of the rim seal by preventing ingestion of mainstream flow. This unexpected outcome was consistently observed across the test matrix for several combinations of purge flow rates and seal clearances - see Figure 11(b). At the lowest flow cloefficient tested $\left(U_{a x} /(\Omega b)=0.45\right)$, the sealing effectiveness for the axisymmetric annulus flow dropped just below that for the vaned configuration at the outer radii.

Phadke and Owen [9] postulated that NGV-induced pressure asymmetries in the annulus gas path drive the hot ingestion mechanism when NGVs are present. The disc pumping effect under these circumstances was generally expected to be significantly lower although both mechanisms might co-exist under certain circumstances. The higher flow coefficient results presented in Figure 10 and Figure 11 are consistent with this statement. However, at higher rotational speeds (or lower flow 
coefficients), Figure 11 challenges the assumption that ingestion will be dominated by the external pressure asymmetries when vanes are fitted. The data shown in Figure 11 indicate that the rotation-induced flow can suppress or mitigate the effects of pressure-driven ingestion. This was also captured by the numerical study conducted by Palermo et al. [23] for similar seal and cavity geometries using unsteady Reynolds-average CFD.

Figure 11(b) shows comparable results for the larger seal gap, for a fixed purge flow rate at $U_{a x} /(\Omega b)=1.01$ and $U_{a x} /(\Omega b)=0.52$. For the axisymmetric annulus flow scenario, increasing rotation results in larger ingestion, aligning with Figure 11(a). For the case with vanes, the results are consistent with the findings from the smaller clearance: better sealing performance at lower flow coefficient is found near the rim. However, the influence of rotation is weaker for the larger clearance. This could be due to purge and pressure-driven mass flows increasing for the larger clearance while disc pumping flows are less dependent on the gap size. However, as the seal clearance is increased by changing the axial spacing between the rotor and stator only, geometrical similarity is lost, particularly in terms of the axial overlap of the chute seal, and this could also account for the different behaviour of the two seals.

\section{Overall sealing effectiveness dependencies}

Figure 12 presents the outcome of the smaller seal clearance studies as a map of sealing effectiveness against the seal-to-rotor rim velocity ratio, $U_{m} /(\Omega b)$, also referred to as non-dimensional purge flow or purge flow ratio. Data have been obtained at a radius near the rim, $r / b=0.99$, for all rotor speeds and purge flow rates investigated. The colored lines in Figure 12 connect results at the same flow coefficient (rotor disc speeds) whilst the dotted black lines join the data at constant purge flow rate for different rotor disc speeds to assess the effect of flow coefficient. Results are compared with the test case with external axisymmetric flow and the analytical correlation for disc pumping effect given by Eq. 1 with $k=1$.

Higher seal-to-axial velocity ratios consistently provide better sealing by increasing the pressure inside the cavity so that less external fluid is drawn into the cavity. The effect of reducing flow coefficient (increasing rotor speed) at a constant purge supply can be analysed by following each of the black dotted lines from right to left. At low values of $U_{m} / U_{a x}$ (where significant ingestion occurs) strong sensitivity to flow coefficient is evident. For example, the results for $U_{m} / U_{a x}=0.08$ reveal an important $30 \%$ improvement of the sealing effectiveness as the flow coefficient decreases from 4.05 to 0.45 . This trend was observed along the flat surface in the stator cavity wall in Figure 11(a) and it can be related to the reduced amplitude of the nondimensional annulus pressure asymmetries in Figure 8(b). The $U_{a x} /(\Omega b)=4.05$ test case represents a virtually stopped rotor in which the disc pumping effect is negligible. The sealing effectiveness values at $U_{a x} /(\Omega b)>1$ in Figure 12 are very similar (corresponding to $1000 \mathrm{rpm}$ and $4000 \mathrm{rpm}$ ), indicating that pressure-driven ingestion dominates at lower speeds. A reduction of the sealing capability at lower rotor disc speeds was identified by Savov et al. [15] for other geometries. As shown in Table 2, both rotational Reynolds number $\operatorname{Re}_{\emptyset}$ and flow coefficient $U_{a x} /(\Omega b)$ vary with rotor speed in the present experiments. Previous rim sealing studies have found that for a fixed $U_{a x} /(\Omega b)$ there is little or no dependency on rotational Reynolds number.

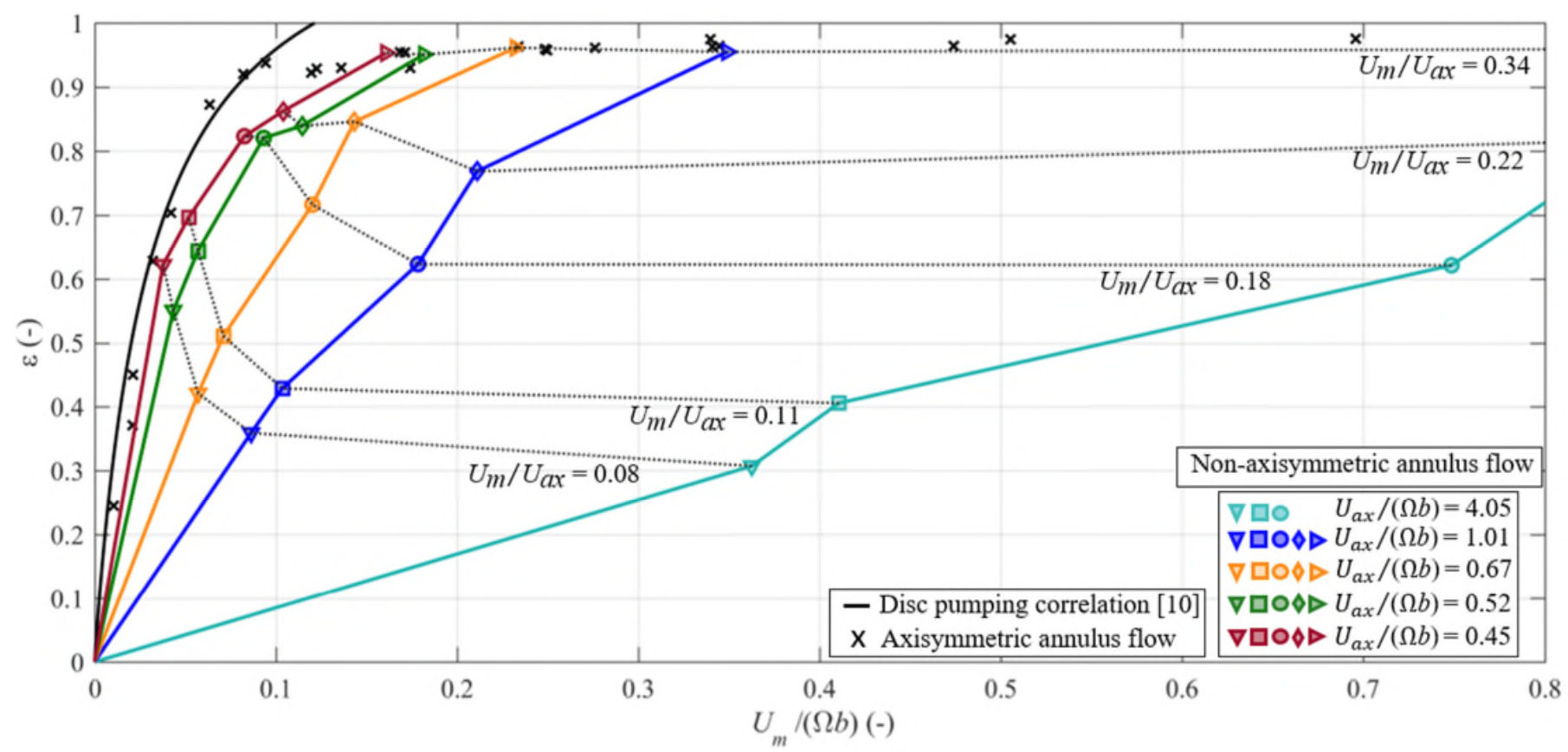

Figure 12: Map of sealing effectiveness against the non-dimensional purge flow ratio, $U_{m} /(\Omega b)$ at $r / b=0.99$ and $s_{c}=4.2 \times 10^{-3}$ for different seal-to-axial velocity ratios and flow coefficients under axisymmetric and non-axisymmetric external flow. 
Thus the effects of rotor speed shown here can be interpreted, at least to first order, as the effects of the flow coefficient which is equivalent to the ratio $\operatorname{Re}_{a x} / \operatorname{Re}_{\emptyset}$ used by Phadke and Owen [9]. Figure 12 shows that ingestion is pressure-driven at high values of the flow coefficient, such as those that might occur in low pressure turbines. At high purge flow rates, Figure 12 reveals an almost invariant sealing effectiveness value for changes in flow coefficient. It becomes apparent that a fully sealed cavity is not reached under any of the test conditions considered during this investigation, highlighting the complexity of the interaction of the purge and annulus flows in the rim seal region. For low flow coefficients, such as might be found in core turbines, both rotational and pressure-driven effects may be important. As the flow coefficient reduces to 0.45 the sealing effectiveness approaches values associated with rotationally-driven ingestion. This is particularly the case at low purge flow rates. This effect of disc speed has important implications for engines, especially core turbines which usually have flow coefficients in the range where the sealing effectiveness is sensitive to rotor disc speed.

Variations in flow coefficient due to changes in tangential velocity at the rotor rim affect the velocity triangles by inducing a variation of the annulus flow angle. The closest agreement between the NGV exit tangential velocity and that of the purge flow is found at $U_{a x} /(\Omega b)=0.45$. This could imply that similarity in the swirl component of the mainstream and the outbound purge flow reduces the shear between the two streams and improves the sealing capability of the rim seal. CFD prediction from Palermo et al. [23] captured some of the trends described in this paper. In particular, at lower flow coefficient, CFD predicted that the chute seal may offer some insensitivity to pressure-driven effects, in agreement with measurements. However, the CFD underpredicted the levels of ingestion.

\section{Comparison with previous work}

The results from the current research are compared in Figure 13 with the data for a chute seal obtained by Horwood et al. [17] in a turbine rig at the University of Bath. The flow coefficient for the turbine was 0.35 , compared to 0.45 for the results shown from the ORF. However, Horwood et al.'s experiments included effects of the rotating blades and a different vane design. Values of effectiveness are obtained at $r / b=0.96$ in the ORF and the facility at the University of Bath.

An extraordinary good agreement is evident despite the different test conditions. Sealing effectiveness measurements at the University of Sussex for a chute seal by Gentilhomme [18], as presented in references [19] and [23], also show some agreement with the present results. The Sussex experiments were conducted in a turbine rig with a flow coefficient $\sim 0.6$, and included a significant density difference between the purge and main annulus flows. Calculation of $U_{m} /(\Omega b)$ values for the University of Sussex data was subject to some uncertainty so these are not shown in Figure 13. Nonetheless, the similarity of the results with data from other research facilities suggests some insensitivity to turbine design at low flow coefficients, which is encouraging for extrapolation of rig data to engine conditions.

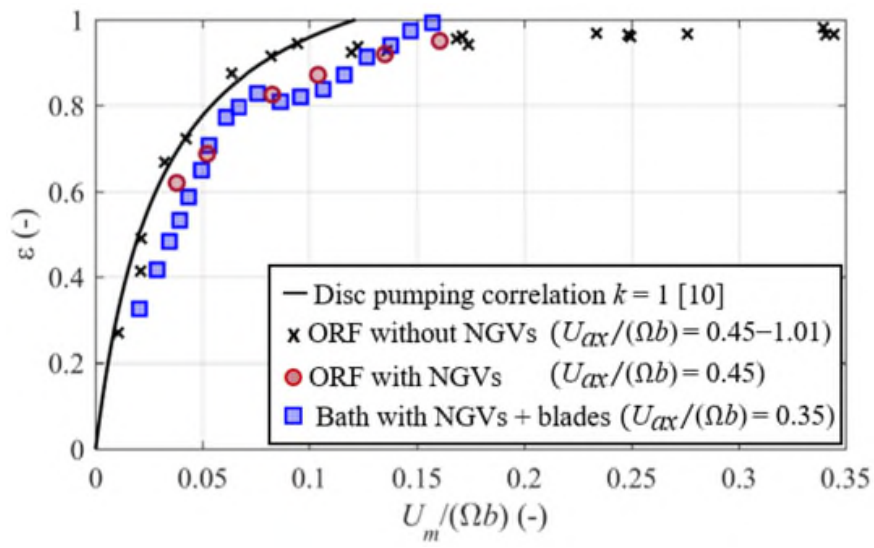

Figure 13: Comparison of sealing performance of a chute seal under different external flow conditions at $r / b=0.96$.

Engine representative conditions in scaled test facilities are simulated by matching the relevant non-dimensional parameters. The non-dimensional purge flow $U_{m} /(\Omega b)$ defines the extent of ingestion and the turbulent flow parameter characterises the flow structure inside the cavity. Values between 0 and 0.1 are typically found in aero-engines for both quantities thus this research is considered to represent the flow behaviour in an engine cavity. Characteristic values of rotational Reynolds number in aeroengines are of the order of $10^{7}$. Despite the range of $\mathrm{Re}_{\varnothing}$ covered in this study being an order of magnitude below engine-realistic conditions, Figure 12 suggests that extrapolation to values of rotor disc speed found at engine operating conditions would intensify the disc pumping effect. This is the case especially for high pressure turbines which usually have flow coefficients in the range where the sealing performance displays high sensitivity to rotational speed.

Considering correlation of results, it is also of interest to compare present measurements with the orifice model. While numerous variations of the orifice model are available, Hamabe and Ishida's version [11] assuming a sinusoidal pressure distribution and constant discharge coefficient has been used for an initial comparison. The amplitude of the circumferential pressure variations have been obtained from the data shown in Figure 8 for $s_{c}=4.2 \times 10^{-3}$ and $U_{m} / U_{a x}=0.08$. Figure 14 compares sealing effectiveness at flow coefficients of 0.45 and 1.01 with the orifice model at a radial position $r / b=0.96$, assuming discharge coefficients of 0.4 and 0.6 at these two conditions. For $U_{a x} /(\Omega b)=1.01(4000 \mathrm{rpm})$, the orifice model fits the measurements reasonably well with $C_{d}=0.6$. At $U_{a x} /(\Omega b)=0.45(9000 \mathrm{rpm}), C_{d}=0.4$ fits the data better at low effectiveness, and $C_{d}=0.6$ fits better at high sealing effectiveness. The disc pumping effect correlation by Chew [10] is also included for comparison. The experimental data and orifice model predictions approach the disc pumping correlation at low flow coefficients. In addition, Figure 14 reveals that discharge coefficients in the orifice model predictions could be considered as a function of flow coefficient, reducing as the orifice model predictions approach values for rotationally-driven ingestion. 


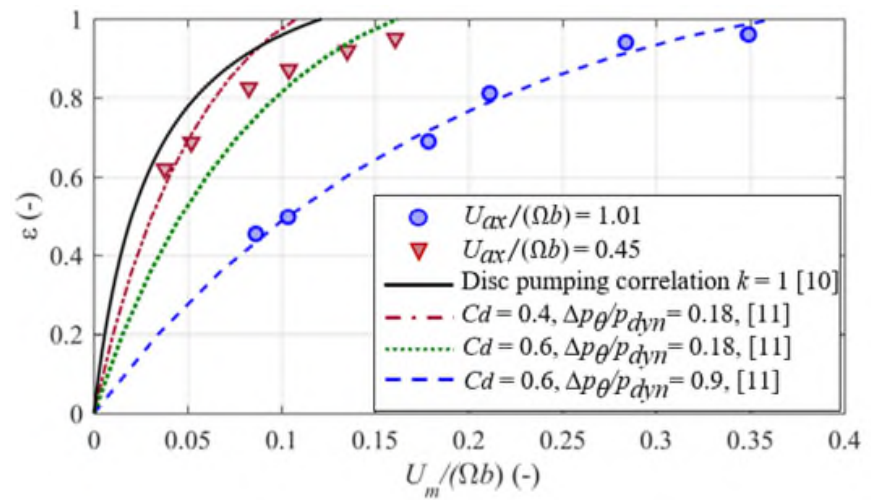

Figure 14: Comparison of experimental data against orifice model prediction from Hamabe and Ishida [11] and Chew [10].

\section{CONCLUSIONS}

The performance of a rim chute seal and cavity subject to rotationally-driven and pressure-driven ingestion has been studied. Main gas path test configurations with no flow and axisymmetric flow simulated conditions of rotationally-driven ingestion. The introduction of turbine vanes upstream of the seal superimposed pressure-driven effects by creating a swirl velocity component in the annulus flow and generating circumferential pressure and velocity asymmetries. Thus two of the main drivers for mainstream gas ingestion in a turbine have been investigated.

Steady pressures have been acquired inside the cavity and on the reduced annulus casing. The radial profile of pressure coefficient in the cavity revealed the presence of two different forced vortex strengths in the upper and lower parts of the cavity that corresponded to distinct geometrical regions in the stator wall. The circumferential mean pressure coefficient (with dynamic head referenced to the annulus flow velocity) was measured in the annulus over a vane pitch downstream of the NGVs, and showed significant circumferential variation which was independent of disc speed. At all test conditions, the annulus pressure asymmetries were significant compared to rotational effects. At the highest rotor speed tested, the minimum-tomaximum circumferential pressure variation in the annulus was approximately $20 \%$ of the dynamic head associated with the rotor disc rim speed.

Ingestion of mainstream flow into the rotor disc cavity has been evaluated using the tracer gas technique to quantify the sealing effectiveness of the chute seal. Results under purely rotationally-driven ingestion have been compared with experimental data of axial and radial seals available in the open literature and existing correlations. The sealing capability of the chute seal under these conditions outperformed that of an axial seal with similar axial clearance but it was lower than expected.

The introduction of vanes led to reduced overall sealing effectiveness. This effect was most severe at the largest flow coefficients studied. Decreasing the flow coefficient (by increasing the rotor disc speed with the other parameters held constant), improved sealing effectiveness. At the lowest flow coefficient tested, the sealing effectiveness approached that associated with rotationally-driven ingestion alone. Comparison of the radial distribution of sealing effectiveness inside the cavity for axisymmetric and non-axisymmetric flow showed opposing trends as rotor disc speed increased (and flow coefficient decreased). A reduction in sealing performance for higher disc speeds was observed in the absence of annulus flow and for an axisymmetric annulus flow. However, with vanes present, the lowest values of sealing effectiveness were found at the lowest rotational speeds investigated, with a considerable improvement at higher speeds. This finding is of particular relevance for core turbines (in which the flow coefficients are in this range) since the disc pumping effect would be intensified and sealing capability improved at the rotational speeds found at engine operating conditions.

Plots of sealing effectiveness against non-dimensional purge flow ratio showed a remarkable influence of rotor disc speed (or flow coefficient) on the sealing capability of the chute seal, especially at low purge rates and high rotational speeds. Agreement with the correlation developed by Chew [10] for the purely rotationally-driven ingestion was found. Departure from this condition (with vanes fitted) increased with flow coefficient. At the lowest value considered, $U_{a x} /(\Omega b)=0.45$, the effectiveness is close to the rotationally-dominated condition. For $U_{a x} /(\Omega b)>1$, ingestion is dominated by annulus flow effects. Notwithstanding these clear trends, for higher levels of purge flow with effectiveness above $\sim 0.8$, the results suggest some complex interactions of the purge and annulus flows.

Comparison to an orifice model for pressure-driven ingestion suggests an interesting dependence of the discharge coefficient on flow coefficient. Remarkable agreement has been found when the data of this investigation has been compared to that of previously published studies of similar chute seals at Sussex and Bath Universities. These previous studies were both conducted in turbine rigs with vanes and rotor blades present, and had flow coefficients of $\sim 0.35$ and $\sim 0.6$, respectively. The resemblance of experimental results from different test facilities reveals a certain degree of insensitivity of turbine design at low flow coefficient, which is promising for extrapolation to engine conditions.

\section{ACKNOWLEDGMENTS}

The authors would like to thank Rolls-Royce plc and Innovate UK for funding this research through the grant TSB 113076. The contributions of Peter Smout and Prof. Kam Chana are gratefully acknowledged as well as the technical support provided by Gregory King, Sunny Chana and James Carter.

\section{REFERENCES}

[1] Johnson, B.V., Mack, G.J., and Paolillo, R.E., 1994, "Turbine rim seal path flow ingestion mechanisms." AIAA paper 94.

[2] Scobie, J.A., Sangan, C.M., Owen, M., and Lock, G.D., 2016, "Review of Ingress in Gas Turbines." ASME. J. Eng. Gas Turbines Power, December 2016; 138(10): 120801, doi: 10.1115/1.4033938

[3] Chew, J.W., Gao, F., and Palermo, D.M., 2018, "Flow mechanisms in axial turbine rim sealing." Proc. Inst. Mech. 
Eng. Pt. C J. Mechan. Eng. Sci., doi: 10.1177/ 0954406218784612

[4] Phadke, U.P., and Owen, J.M., 1988, "Aerodynamic aspects of the sealing of gas-turbine rotor-stator systems: Part 1: The behavior of simple shrouded rotating-disk systems in a quiescent environment." Int. J. Heat Fluid Fl., 9(2): 98-105, doi: 10.1016/0142-727X(88)90060-4

[5] Beard, P. F., Gao, F., Chana, K. S., and Chew, J., 2017. "Unsteady Flow Phenomena in Turbine Rim Seals." ASME. J. Eng. Gas Turbines Power. March 2017; 139(3): 032501, doi: $10.1115 / 1.4034452$

[6] Gao, F., Chew, J. W., and Marxen, O., 2020. "Inertial waves in turbine rim seal flows". Physical Review Fluids, 5(2), p. 024802 .

[7] Bayley, J., and Owen, J. M., 1970, “The Fluid Dynamics of a Shrouded Disk System with a Radial Outflow of Coolant," ASME. J. Eng. Power., 92(3): 335-341, doi: $10.1115 / 1.3445358$

[8] Abe, T., Kikuchi,J., and Takeuchi, H., 1979, "An Investigation of Turbine Disc Cooling (Experimental Investigation and Observation of Hot Gas Flow into a Wheel Space).” In: Third CIMAC congress, Vienna, paper no. GT30.

[9] Phadke, U.P., and Owen, J.M., 1988, "Aerodynamic aspects of the sealing of gas-turbine rotor-stator systems: Part 2: The performance of simple seals in a quasiaxisymmetric external flow." Int. J. Heat Fluid Fl., 9(2): 106-112, doi: 10.1016/0142-727X(88)90061-6

[10] Chew, J.W., 1991, "A Theoretical Study of Ingress for Shrouded Rotating Disc Systems With Radial Outflow." ASME. J. Turbomach., January 1991; 113(1): 91-97, doi: $10.1115 / 1.2927742$

[11] Hamabe, K., and Ishida, K. "Rim Seal Experiments and Analysis of a Rotor-Stator System With Nonaxisymmetric Main Flow." Proceedings of the ASME 1992 International Gas Turbine and Aeroengine Congress and Exposition. Volume 1: Turbomachinery. Cologne, Germany. June 1-4, 1992. V001T01A060. ASME., doi: 10.1115/92-GT-160

[12] Green, T., and Turner, A.B., 1994, "Ingestion Into the Upstream Wheelspace of an Axial Turbine Stage." ASME. J. Turbomach., April 1994; 116(2): 327-332, doi: $\underline{10.1115 / 1.2928368}$

[13] Bohn, Dieter, Johann, Erik, and Krüger, Uwe. "Experimental and Numerical Investigations of Aerodynamic Aspects of Hot Gas Ingestion in Rotor-Stator Systems With Superimposed Cooling Mass Flow." Proceedings of the ASME 1995 International Gas Turbine and Aeroengine Congress and Exposition. Volume 1: Turbomachinery. Houston, Texas, USA. June 5-8, 1995. V001T01A034. ASME. doi: 10.1115/95-GT-143

[14] Cao, C., Chew, J.W., Millington, P.R., and Hogg, S.I., 2004, "Interaction of Rim Seal and Annulus Flows in an Axial Flow Turbine." ASME. J. Eng. Gas Turbines Power, October 2004; 126(4): 786-793, doi: 10.1115/1.1772408

[15] Savov, S. S., Atkins, N. R., and Uchida, S., 2017, "A Comparison of Single and Double Lip Rim Seal
Geometries". ASME. J. Eng. Gas Turbines Power. November 2017; 139 (11):112601, doi: 10.1115/1.4037027

[16] Hualca, F. P., Horwood, J. T. M., Sangan, C. M., Lock, G. D., and Scobie, J. A., 2020, "The Effect of Vanes and Blades on Ingress in Gas Turbines." ASME. J. Eng. Gas Turbines Power. February 2020; 142(2): 021020. doi: $10.1115 / 1.4045149$

[17] Horwood, J. T. M., Hualca, F. P., Wilson, M., Scobie, J. A., Sangan, C. M., Lock, G. D., Dahlqvist, J., and Fridh, J., 2020, "Flow Instabilities in Gas Turbine Chute Seals." ASME. J. Eng. Gas Turbines Power. February 2020; 142(2): 021019, doi: $10.1115 / 1.4045148$

[18] Gentilhomme, O. J. P., 2004. "Turbine rim seal ingestion". $\mathrm{PhD}$ thesis, University of Sussex.

[19] Boudet, J., Autef, V., Chew, J., Hills, N., Gentilhomme, O., 2005, "Numerical Simulation of rim seal flows in Axial Turbines", Aeronautical Journal, 109(1098), pp. 373-383, doi: 10.1017/S000192400070042X

[20] Ainsworth, R.W., Schultz, D.L., Davies, M.R.D., Forth, C.J.P., Hilditch, M.A., Oldfield, M.L.G., Sheard, A.G. "A Transient Flow Facility for the Study of the ThermofluidDynamics of a Full Stage Turbine Under Engine Representative Flow Conditions," Proceedings of the ASME 1988 International Gas Turbine and Aeroengine Congress and Exposition. Volume 4: Heat Transfer; Electric Power; Industrial and Cogeneration. Amsterdam, The Netherlands. June 6-9, 1988. V004T09A022. ASME. doi: $10.1115 / 88-G T-144$

[21] Bru Revert, A., Beard, P. F., Chew, J. W., Bottenheim, S. "Sealing Performance of a Turbine Rim Chute Seal Under Rotationally-Induced Ingestion", $18^{\text {th }} \quad$ ISROMAC Conference, April 2020.

[22] Sangan, C.M., Pountney, O.J., Zhou, K., Owen, J. M., Wilson, M., and Lock, G. D., 2013, "Experimental Measurements of Ingestion Through Turbine Rim Seals. Part II: Rotationally Induced Ingress." ASME. J. Turbomach. March 2013; 135(2): 021013, doi: $10.1115 / 1.4006586$

[23] Palermo, Donato M., Gao, Feng, Chew, John W., and Beard, Paul F. "Effect of Annulus Flow Conditions on Turbine Rim Seal Ingestion." Proceedings of the ASME Turbo Expo 2019: Turbomachinery Technical Conference and Exposition. Volume 5B: Heat Transfer. Phoenix, Arizona, USA. June 17-21, 2019. V05BT15A004. ASME doi: $\underline{10.1115 / G T 2019-90489}$ 